\title{
Components of Heuristic Strategy: Evaluation of Stories with DST tool on Touch Screen Tablet
}

\author{
Hashiroh Hussain \\ Institut Pendidikan Guru \\ Kampus Sultan Abdul Halim 08000 Sungai Petani, \\ Kedah, Malaysia
}

\author{
Norshuhada Shiratuddin \\ Awang Had Salleh \\ Graduate School \\ Universiti Utara Malaysia \\ 06010 Sintok, Kedah, Malaysia
}

\begin{abstract}
Storytelling technique is an effective method for teaching and learning process among educators due to its easy and fast technique. With the boost of technology on mobile devices such as tablet and smart phone, creating stories become easy with a tool on natural interfaces. Compared to the size with the smart phone, interaction of tablet works effectively with flick/fling and pinch/spread function which contributes the realistic details by making changes in the size and editing character in the creation of stories. However, the lack of established guidelines (heuristics) for touch screen interaction has led to misunderstanding of heuristic on mobile applications specifically on creating stories. Therefore, heuristic strategy is proposed to evaluate the digital storytelling (DST) tool that have been designated. The strategy consists of three components: Interface, DST and Multimedia. Next, in order to determine the relationship among the three components, a Pearson Correlation Analysis is employed. The results indicate that the strategy is useful and potential to be implemented in similar DST tool applications.
\end{abstract}

\section{Keywords}

Tablet, heuristic, digital storytelling, tool

\section{INTRODUCTION}

Storytelling is an effective method of teaching and learning process among educators due to its easy and fast technique [12]. This approach is popular and suitable for teaching all subjects as it can increase communication and memory [16]. [22] claims that the usage of computer technology in the storytelling method has a positive impact compared to the traditional storytelling method. Its main objective is for data exploration by presenting and communicating to an audience [2]. Narrative stories can be conveyed to the audience in a variety of ways, whether oral, scripting stories, cartoons and movies.

Next section introduces a little background of digital storytelling and followed by the heuristic strategy used in the evaluation for creating stories. The next section explains the methods and findings of the data retrieved regarding the heuristic strategy and the relationship among the components of the heuristic. This article ends with the discussion and future works of the study conducted.

\subsection{Review of Literature}

The idea of a narrative entertainment to connect audience through media and technology has comprehend the concept of DST [11]. [14] recommends that DST should be instilled with the multimedia technology to meet the requirement of narrative communication. While [8] summarizes that DST is a short story, a video-narrative created by a combination of sound, image, music or sound and animation.
In order to understand the purpose of a story with quick and easy way, a storytelling tool is required [19]. The tool should work on tablet so that it could contribute the realistic details by making changes in the size and editing character, in the creation of stories [20].This is due to the advantage of using tablet in the class room has resolved certain problems dealing with interaction of tablet. The natural user interface (NUI) using touch screen interaction serves flick/fling and pinch/spread function [7]. In addition, mobile device such as tablet is preferable mobile device because it is in small sized electronic applications and enable to process network facilities [5]. Other special elements are lightweight, fast startup, efficient high-performance graphics and memory to help users in completing any given task and reducing errors [7]. This led to an innovative product design by using an imagebased interaction on NUI [9]. Method for testing a product can be applied by using a heuristic strategy which is increasingly popular practiced in designing product.

A tool is required for designers especially for novice designers in the creation of stories for educational purposes. However, existing design tool does not support narratives [23] and not designed for educational purposes [15]. Thus, restrictions on usability of interface design tools with limited functions [18] and lack of established guide lines on the NUI interaction has led to misunderstanding of heuristic on mobile devices [13].

\subsection{Heuristic Strategy}

The Human-Computer Interaction (HCI) discipline provides a complete set of techniques to evaluate usability of interactive systems. Heuristic strategy is the evaluation technique developed for usability of an application in order to find out how users easily and efficiently can achieve the application objectives [21]. This method has become popular because of its cost effectiveness in the area of HCI, especially for interactive product [1]. However, there are several studies made on the user interface, but lack studies made on the interaction design.[10] extended 11 heuristics from Nielsen's heuristic in the evaluation for interface of mobile devices in the android based application. While [13] suggested several fundamental principles of interaction design which are independent of technology namely as: visibility, feedback, consistency, non-destructive operations, discoverability and scalability. [4] also present 7 guidelines to help design and evaluate touchscreen solutions for mobile handsets. There are screen size matters, touchscreen responsiveness, navigation \& efficiency of use, the virtual keypad and icon design. However, [5] manage to evaluate and validate a set of 12 heuristics which are specific for the evaluation of mobile device interfaces by performing three types of experiments: inquiry tests, heuristic evaluation and experts' opinion. The studies took into account Nielsen's original heuristics by modifying the heuristics definitions, in order to support the 
understand ability of the principle. Therefore, this study proposes a set of heuristics from different aspects, namely as interface, multimedia and DST to be implemented in the similar DST tool application. The heuristics is expected to be useful in evaluating better tools for creating stories on touch screen tablet.

\subsection{Components of Heuristic Strategy}

The heuristic strategy for evaluating DST tool involved three components: Interface (IN), Digital Storytelling (DST) and Multimedia (MM). As shown in Table 1, Interface component describes the interaction of touch screen for mobile devices [6]. The interface allows users to interact with other multimedia elements such as text, image and audios while developing stories. A good interface usability ensures them to have interest in the creation of stories and the interaction of object. Therefore, elements of multimedia as added component in this study for a better interaction. As listed in Table 2, the Multimedia component consists of 8 sub heuristics which involved on multimedia elements [3]. Thus, multimedia is a major contribution in the development of digital storytelling [17]. Since, the major intention of this study is to create stories, DST is the other main components should be added in determining the applicable heuristics for this study. Table 3 presents the elements of DST which are validated and reviewed by prominent experts [23].

Table 1: Interface Components(IN)

\begin{tabular}{|l|l|}
\hline Code & Heuristic \\
\hline IN01 & Visibility of system \\
\hline IN02 & Match between system status and the real world \\
\hline IN03 & User control and freedom \\
\hline IN04 & Consistency and standards \\
\hline IN05 & Error prevention \\
\hline IN06 & Minimize the user's memory load \\
\hline IN07 & Customization and shortcuts \\
\hline IN08 & Flexibility and efficiency of use \\
\hline IN09 & Aesthetic and minimalist design \\
\hline IN10 & $\begin{array}{l}\text { Help users recognize, diagnose, and recover from } \\
\text { errors }\end{array}$ \\
\hline IN11 & Help and documentation \\
\hline IN12 & Physical interaction and ergonomics \\
\hline
\end{tabular}

Table 2: Multimedia Components(MM)

\begin{tabular}{|l|l|}
\hline Code & Heuristic \\
\hline MM01 & $\begin{array}{l}\text { Each multimedia element used serves a clear } \\
\text { purpose }\end{array}$ \\
\hline MM02 & $\begin{array}{l}\text { Usage of multimedia elements are suitable with } \\
\text { the content }\end{array}$ \\
\hline MM03 & $\begin{array}{l}\text { Combination of multimedia elements are } \\
\text { adequate }\end{array}$ \\
\hline MM04 & $\begin{array}{l}\text { The presentation of multimedia elements is well } \\
\text { managed. }\end{array}$ \\
\hline MM05 & Numbers of multimedia elements for each screen \\
\hline
\end{tabular}

\begin{tabular}{|l|l|}
\hline MM06 & $\begin{array}{l}\text { is not more than 2 elements } \\
\text { meaningfully the information provided }\end{array}$ \\
\hline MM07 & The quality of multimedia elements used is good. \\
\hline MM08 & $\begin{array}{l}\text { The use of multimedia elements enhances the } \\
\text { content presentation. }\end{array}$ \\
\hline
\end{tabular}

Table 3: DST Components (DST)

\begin{tabular}{|l|l|}
\hline Code & Heuristic \\
\hline DST01 & $\begin{array}{l}\text { The point of story can be the perspective of first } \\
\text { person or third person }\end{array}$ \\
\hline DST02 & Intention of the story is clearly defined \\
\hline DST03 & The story is personalized to engage viewer \\
\hline DST04 & $\begin{array}{l}\text { Dramatic question raised during the progress of } \\
\text { the story }\end{array}$ \\
\hline DST05 & $\begin{array}{l}\text { The ability of story to engage audience's } \\
\text { attention }\end{array}$ \\
\hline DST06 & The use of voice for a better impact \\
\hline DST07 & $\begin{array}{l}\text { The use of soundtrack to support emotional } \\
\text { value and deliver message }\end{array}$ \\
\hline DST08 & The pace of story changed by the music tempo \\
\hline DST09 & \begin{tabular}{l} 
The story has introduction, body and conclusion \\
\hline DST10
\end{tabular} $\begin{array}{l}\text { The expression using media contents(image and } \\
\text { sound) rather than words }\end{array}$ \\
\hline DST11 & $\begin{array}{l}\text { Materials used are significant content to the plot } \\
\text { of story }\end{array}$ \\
\hline DST12 & $\begin{array}{l}\text { User collaborates with other user in order to } \\
\text { construct story }\end{array}$ \\
\hline DST13 & $\begin{array}{l}\text { User contributes to the creation of story through } \\
\text { interaction of system }\end{array}$ \\
\hline DST14 & Use sufficient material to construct story \\
\hline
\end{tabular}

A preliminary study on the usage of DST tool is conducted before implementing the strategy. The main objective of this study is to find out their tool preferences in the process of creating stories. Demographic samples and data responses from a checklist of DST tool preferences are analysed with descriptive technique. The targeted samples are lecturers, preserviced and in-service teachers in the one of Institute of Teacher Training in northern region of Peninsular Malaysia.

As illustrated in able 4, about 18 of the respondents are female and the remainder male including $30.3 \%$ are lecturers, $48.5 \%$ are pre-serviced teachers and $21.2 \%$ are in service teachers. The results showed that $54.5 \%$ respondents used DST tool but majority respondents prefer Microsoft Power point desktop as their DST tool with $48.4 \%$ users, $12 \%$ used Movie maker and $9 \%$ used Prezi as shown in Table 5.

Table 4: Demographic profiles of respondents

\begin{tabular}{|l|r|r|r|r|}
\hline Respondents & Male & Female & \multicolumn{2}{|c|}{ Total } \\
\hline & & & Frequency & Percent \\
\hline Lecturers & 7 & 3 & 10 & $30.3 \%$ \\
\hline $\begin{array}{l}\text { Pre-service } \\
\text { teachers }\end{array}$ & 7 & 9 & 16 & $48.5 \%$ \\
\hline $\begin{array}{l}\text { In-service } \\
\text { teachers }\end{array}$ & 1 & 6 & 7 & $21.2 \%$ \\
\hline Total & 15 & 18 & 33 & \\
\hline
\end{tabular}


Table 5: Preferences for DST Tool

\begin{tabular}{|l|r|r|}
\hline Tool & Frequency & Percent \\
\hline Microsoft PowerPoint(desktop) & 16 & $48.4 \%$ \\
\hline Movie maker & 12 & $12.0 \%$ \\
\hline Prezi & 3 & $9 \%$ \\
\hline Others & 2 & $6 \%$ \\
\hline Total & 33 & \\
\hline
\end{tabular}

The evaluation for creating stories is initiated with the introduction of other DST tool which works on a touch screen tablet with easy interaction. A comparative analysis is employed for selecting the DST tool as tabulated in Table 6 .

Table 6: Comparison of different tools

\begin{tabular}{|l|l|l|l|}
\hline Design Feature & A & B & C \\
\hline Drawing & $\mathrm{X}$ & $\mathrm{X}$ & $\mathrm{NA}$ \\
\hline Use image from libraries & $\mathrm{X}$ & $\mathrm{X}$ & $\mathrm{X}$ \\
\hline $\begin{array}{l}\text { Take and edit picture from } \\
\text { camera }\end{array}$ & $\mathrm{X}$ & $\mathrm{X}$ & $\mathrm{X}$ \\
\hline Use video from libraries & $\mathrm{X}$ & $\mathrm{X}$ & $\mathrm{NA}$ \\
\hline Take and edit video & $\mathrm{X}$ & $\mathrm{X}$ & $\mathrm{NA}$ \\
\hline Use audio from libraries & $\mathrm{X}$ & $\mathrm{X}$ & $\mathrm{X}$ \\
\hline Record and edit audio & $\mathrm{X}$ & $\mathrm{X}$ & $\mathrm{X}$ \\
\hline Type and edit text & $\mathrm{X}$ & $\mathrm{X}$ & $\mathrm{X}$ \\
\hline Share data from server & $\mathrm{X}$ & $\mathrm{X}$ & $\mathrm{X}$ \\
\hline Export in digital form & $\mathrm{X}$ & $\mathrm{X}$ & $\mathrm{X}$ \\
\hline Touch Screen & $\mathrm{X}$ & $\mathrm{X}$ & $\mathrm{X}$ \\
\hline Online application using tablet & $\mathrm{X}$ & $\mathrm{NA}$ & $\mathrm{X}$ \\
& & & \\
\hline
\end{tabular}

A:Storykit

B:Photostory

C:Stroyboardthat

NA: Not available

The study decides that Storykit is designated because its suitable features in the creation of DST, namely as: free, easy to use, touch screen and user -friendly. It will be used as DST tool in the implementation of the heuristic strategy as shown in Figure 1. Next, the tool is evaluated using the proposed heuristics strategy and the results are then further discussed. The heuristic strategy is proposed for its cheap and fast mechanism in measuring the usability of a tool. Recent studies indicate that the strategy is useful and potential to be implemented for applications with the evaluation by users [21].

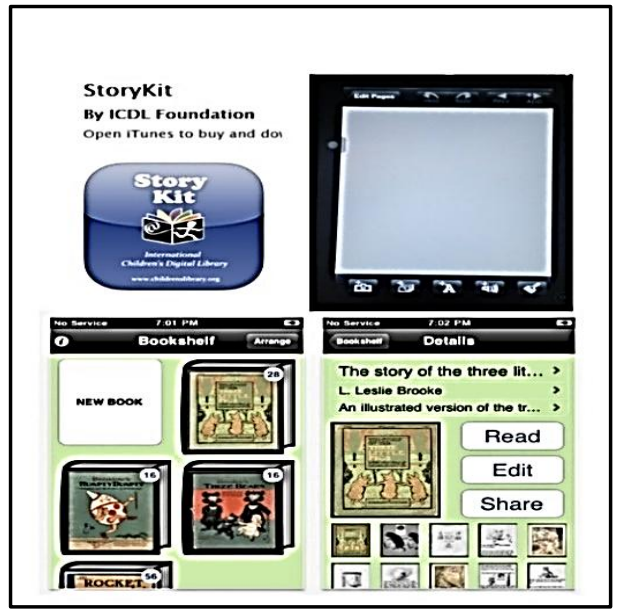

Figure 1: Storykit's Interface

\section{METHODOLOGY}

A total of 41 pre-service teachers who have experienced using mobile devices and creating multimedia material are selected as respondents in this study. The study takes place in their class room during their project session in the creation of multimedia material. A briefing on DST tool is conducted to give an overview of its application for creating stories. This is an advantage for them because currently they have to complete their major project at that time. Previously, they used storyboard template using Microsoft PowerPoint desktop as a tool in creating stories. The introduction of the DST tool has fascinated their attention and they are excited to use it.

In implementing the task given, they are divided into groups in attempting the usage of the tool for about an hour guided by the researcher as shown in Figure 2. A set of questionnaire based on 7 Likert scales is used as an instrument to evaluate the usage of the tool. The questions consist of the three components of the heuristics strategy: interface, multimedia and DST (as depicted in Table 1 to 3 )

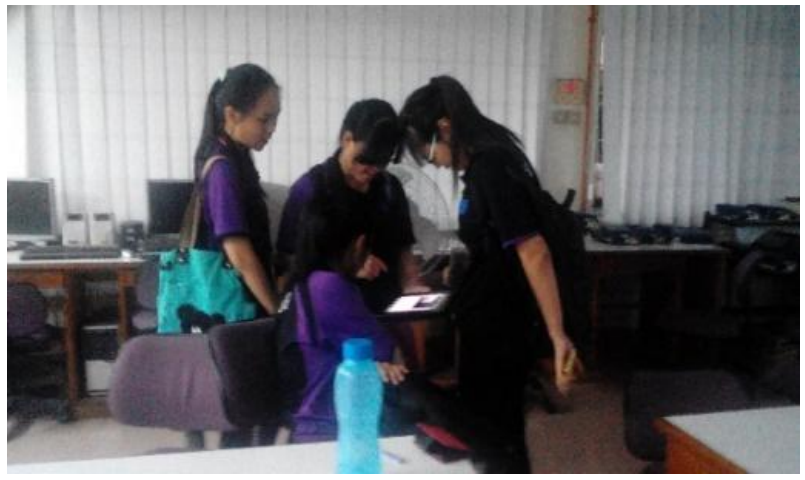

Figure 2: Student is divided into groups to try out DST tool (Storykit)

\section{RESULTS AND DISCUSSION}

This section presents the data analysis of the heuristics strategy and discussion of the main results. The discussion is intended to highlight the findings from the responses obtained. Firstly, the demographic profile of the users who participated in the study as illustrated in Table 7 . Out of 41 users, $80.5 \%$ of the respondents are female and the remainder male. As for race composition, the majority of the respondents are Chinese $(63.4 \%)$, while the rest are Malay $(26.8 \%)$ and other races $(9.8 \%)$ that include Dusun. The results found that 
majority of the respondents with $87.8 \%$ have never used tablet as depicted in Figure 3.

Table 7: Demographic profiles

\begin{tabular}{|l|l|l|l|l|}
\hline Race & Male & Female & \multicolumn{2}{|c|}{ Total } \\
\hline & & & Frequency & Percent \\
\hline Malay & 5 & 6 & 11 & $26.8 \%$ \\
\hline Chinese & 2 & 24 & 26 & $63.4 \%$ \\
\hline Others & 1 & 3 & 4 & $9.8 \%$ \\
\hline Total & 8 & 33 & 41 & $100.0 \%$ \\
\hline
\end{tabular}

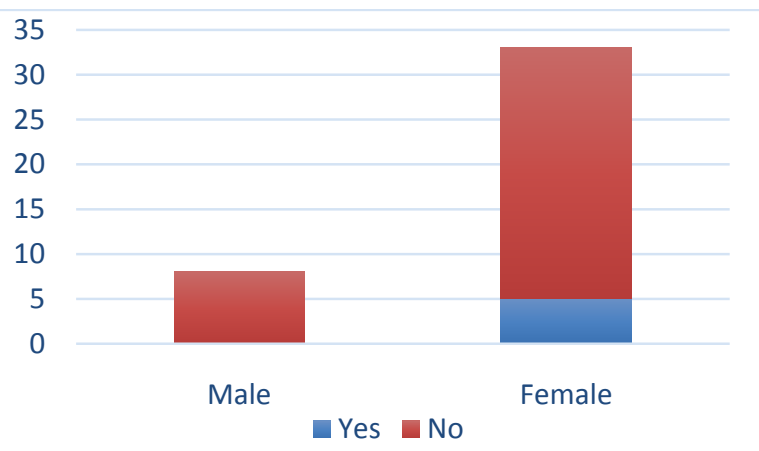

Figure 3: Number of users using tablet

Secondly, findings on the mean score for each component is presented as tabulated in Table 8. The first component of the evaluation is the Interface with the overall mean $=5.78$ and the highest score is IN02 $=6.56$ (Match between system status and the real world). This is concerning with language or instruction used on application that should be clearly explained as there are respondents with non-technical background. Thus, the technical terms may be hard for them to understand. In general, the results showed that the tool is high in term of its interface for the touchscreen aspect. The second component is the Multimedia elements withError! Reference source not found. the overall mean $=6.07$ which the highest score is MM03 $=6.54$ (Combinations of multimedia elements are adequate). This high score is expected, as Multimedia elements contribute to users' attention in creating stories. Dealing with texts, images and audios, the presentation of their stories becomes more interactive and compelling. Finally, the component that is crucial for creating digital stories is the DST. The overall mean $=6.11$ and the highest score is DST05 $=6.39$ (The ability of story to engage audience's attention) and the lowest is DST08 $=5.83$ (The pace of story changed by the music tempo). Having the high average mean score in the analysis, indicates that all three components should be significantly instilled in the proposed heuristics strategy. Although the scores are not consistent, the stories are expected by users to be more compelling rather than simpler version of other DST tool.

Table 8: Mean Score for Each Component

\begin{tabular}{|l|l|l|l|l|}
\hline Code & Interface & Multimedia & DST \\
\hline 01 & 5.71 & 6.15 & 6.00 \\
\hline 02 & 6.56 & 6.22 & 5.95 \\
\hline 03 & 5.83 & 6.54 & 6.15 \\
\hline 04 & 5.71 & 5.88 & 6.02 \\
\hline 05 & 5.32 & 5.24 & 6.39 \\
\hline 06 & 5.39 & 5.85 & 6.22 \\
\hline 07 & & 6.20 & 6.22 \\
\hline
\end{tabular}

\begin{tabular}{|l|l|l|l|l|}
\hline 08 & 5.63 & 6.51 & 5.83 \\
\hline 09 & & 5.63 & & 6.24 \\
\hline 10 & & 6.17 & & 5.90 \\
\hline 11 & & 5.83 & & 6.17 \\
\hline 12 & & 6.15 & & 6.12 \\
\hline 13 & & & & 6.02 \\
\hline 14 & & & & 6.32 \\
\hline Average & 5.78 & 6.07 & 6.11 \\
\hline
\end{tabular}

Thirdly, findings in determining the relationship among the three components are also presented. The data are analysed using Pearson Correlation Analysis to indicate their relationship. Results showed that there is a high positive relationship between DST and multimedia with significant value, $\mathrm{p}<.05$ and $\mathrm{r}=.703$. Furthermore, other results indicate that there are also moderate positive relationship between DST and Interface (, p < .05 and $r=.424)$; Multimedia and Interface $(\mathrm{p}<.05$ and $\mathrm{r}=.495)$ as depicted in Table 9. Therefore, the components are significantly associated to each other in contributing with the heuristic strategy for creating stories.

Table 9 : Pearson Correlation Analysis

\begin{tabular}{|l|l|l|l|}
\hline Component & Multimedia & DST & Interface \\
\hline Multimedia & 1 & .703 & .495 \\
\hline Sig.(1-tailed) & & $.000^{* *}$ & $.001^{* *}$ \\
\hline DST & .703 & 1 & .424 \\
\hline Sig.(1-tailed) & $.000^{* *}$ & & $.003^{* *}$ \\
\hline Interface & .495 & .424 & 1 \\
\hline Sig.(1-tailed) & $.001^{* *}$ & $.003^{* *}$ & \\
\hline N & 41 & 41 & 41 \\
\hline
\end{tabular}

\section{CONCLUSION AND RECOMMENDATIONS}

Generally, the evaluation is conducted in order to find out the usability of the DST tool in creating stories. However, from the past literatures, there are lack of heuristics for creating stories in terms of its interaction. Thus, a heuristics strategy is developed to evaluate the effectiveness of DST tool in the aspects of interface, multimedia and DST (as listed in Table 1 to Table 3). A DST tool is designated based on special features which comply with the objective of this study. The evaluation sessions are successfully conducted using the proposed strategy. The findings concluded that all three components are associated to each other in creating stories. Finally, this also proved that DST tool is useful rather than other manual template used in creating stories. The tool is also expected by users to be easy to edit, user- friendly, using understandable language with adequate material. For future works in this study, further development on proposing a prototype tool for the creation of DST application for high level education according to their own needs and surroundings.

\section{ACKNOWLEDGEMENT}

The authors are thankful to Universiti Utara Malaysia for providing support as grant-in aid for this study and also to all respondents including students and lecturers from Institut Pendidikan Guru Kampus Sultan Abdul Halim, Sungai Petani, Kedah who are involved in this study.

\section{REFERENCES}

[1] Albion, P. (1999). Heuristic evaluation of Educational Multimedia: From theory to practice. ASCILITE99 Conference Proceedings. 
[2] Bongshin, L., Rubaiat, H. K., \& Smith, G. (2013).SketchStory: telling more engaging storieswithdata through freeform sketching. IEEETransactions on Visualization and ComputerGraphics, 19(12), 2416-25. doi:10.1109/TVCG.2013.191

[3] Hasiah, M. O., Azizah, J., \& Rohana, Y. (2013).Usability of Educational Computer Game ( UsaECG ): A Quantitative Approach. Pertanika Journal Science \& Technology, 21(August 2012), 247-260.

[4] Haywood, A., \& Reynolds, R. (2008). Touchscreen : Usability Guidelines (Vol. 2008). United Kingdom.

[5] Inostroza, R., Rusu, C., Roncagliolo, S., Jimenez,C., \& Rusu, V. (2012a). Usability HeuristicsforTouchscreenbased Mobile Devices. In Information Technology: New Generations (ITNG), 2012 Ninth International Conference on Information Technology (pp. 662-667). IEEE Computer Society. doi:10.1109/itng.2012.134

[6] Inostroza, R., Rusu, C., Roncagliolo, S., Jimenez,C., \& Rusu, V. (2012b). Usability Heuristics Validation through Empirical Evidences: A Touchscreen-Based Mobile Devices Proposal. In 31st International Conference of the Chilean Computer Science Society (SCCC) (pp. 60-68). Conference Publishing Services. doi: $10.1109 / \mathrm{sccc} .2012 .15$

[7] Jennings, A., Ryser, S., \& Drews, F. (2013). Touch Screen Devices and the Effectiveness of User Interface Methods. In Proceedings of the Human Factors and Ergonomics Society Annual Meeting (Vol. 57, pp. 16481652). doi:10.1177/1541931213571366

[8] Lambert, J. (2010). Digital Storytelling Cookbook. In Seven Steps of Digital Storytelling (pp. 9-24). Berkeley, CA: Digital Diner Press. Retrievedfromhttp://static.squarespace.com/static/505a3a b2e4b0f1416c7df69a/t/51c3458be4b096e91f04d680/137 1751819981/cookbook_sample.pdf

[9] Liu, W. (2010). Natural user interface- nextmainstream product user interface. In 2010IEEE11th International Conference on ComputerAided Industrial Design \& Conceptual Design(CAIDCD) (Vol. 1, p. Vol 1; 203205). doi:10.1109/CAIDCD.2010.5681374

[10] Machado Neto, O., \& Pimentel, M. da G. (2013). Heuristics for the Assessment of Interfaces of Mobile Devices. In Proceedings of the 19th Brazilian Symposium on Multimedia and the Web (pp. 93-96). New York, NY, USA: ACM. doi: $10.1145 / 2526188.2526237$

[11] Miller, C. H. (2008). Digital Storytelling: A Creator's Guide to Interactive Entertainment: Second Edition. Burlington, USA: Focal express.

[12] Norly, J., Nadia Akma, A. Z., Norasikin, F., \& Nor Zuhaidah, M. Z. (2013). Keberkesanan Penceritaan Digital Interaktif Kanak-Kanak terhadap Penglibatan dalam Pengajaran dan Pembelajaran. In Prosiding Seminar Penyelidikan Pendidikan IPG: International Conference on Early Childhood Education (Vol. 1). North America: IPG Kampus Dato Razali. Retrievedfromhttp://ojs.cakna.net/index.php/spp/article/v iew/875
[13] Norman, D. A., \& Nielsen, J. (2010). Gestural Interfaces :A Step Backward In Usability. Interactions, 17(5), 46-49.

[14] Ohler, J. (2008). Digital Storytelling in the Classroom New Media Pathways to Literacy, Learning, and Creativity (Second Edi.). United States of America: SAGE Publications, Inc. Retrievedfromhttp://www.amazon.com/DigitalStorytelling-Classroom-PathwaysCreativity/dp/1452268258

[15] Rami, M., \& Davies, P. (2012). Integration of Multimedia technologies to facilitate Reflection and Learning, particularly in the area of Digital Storytelling. In International Conference on education and e-Learning Innovations. IEEE Computer Society.

[16] Robiatul A'dawiah, J., \& Halimah, Z. B. (2011) Pembangunan Perisian Cerita Animasi Interaktif untuk Pendidikan Sains. Jurnal Teknologi Pendidikan Malaysia, 1, 5-18. Retrieved from http://www.jtpmmeta.com/resources/141 - JTPM V1N4 - 2011 - Rabiatul - 1.pdf

[17] Robin, B. R. (2008). University of Houston's Educational Uses of Digital Storytelling Website. College of Education, University of Houston.Retrievedfromhttp://www.coe.uh.edu/digitalstor ytelling

[18] Shin, M., Kim, B., \& Park, J. (2005). AR Storyboard: An Augmented Reality based Interactive Storyboard Authoring Tool. In Proceedings of the International Symposium on Mixed and Augmented Reality (ISMAR'05) (pp. 1-2). IEEE Computer Society.

[19] Sova, R., \& Sova, D. H. (2011). Storyboards: a Dynamic Storytelling Tool. In UPA 2006. Usability Professionals Association. Retrieved fromhttp://teced.com/wpcontent/uploads/2011/06/upa200 6_storyboards_a_dynamic_storytelling_tool.pdf

[20] Sutherland, M., \& Maiden, N. (2010). Storyboarding Requirements. Software, IEEE, 27(6), 9-11. doi:10.1109/ms.2010.147

[21] Syamsul Bahrin, Z., \& Norshuhada, S. (2010). Heuristics Evaluation Strategy for Mobile Game-Based Learning. 2010 6th IEEE International Conference on Wireless, Mobile, and Ubiquitous Technologies in Education, 127131. doi:10.1109/WMUTE.2010.27

[22] Tackvic, C. (2012). Digital Storytelling: Using Technology to Spark Creativity. The Educational Forum,76:4,426429.doi:10.1080/00131725.2012.707562

[23] Tenh, H. K., Norshuhada, S., \& Harryizman, H. (2012). Core Elements of Digital Storytelling from Experts' Perspective. Knowledge Management International Conference (KMICe) 2012, (July), 397-402. Retrieved from http://www.kmice.cms.net.my/ProcKMICe/KMICe2012/ PDF/CR163.pdf

[24] Truong, K. N., Hayes, G. R., \& Abowd, G. D. (2006).Storyboarding:AnEmpiricalDetermination of Best Practices and Effective Guidelines. In DIS '06 Proceedings of the 6th conference on Designing Interactive systems (pp. 12-21). NY, USA:ACMNewYork.doi:10.1145/1142405.1142410 